\title{
MEDICAL GOLONIZATION OF THE NEW WORLD
}

\author{
by
}

\section{FRANGISGO GUERRA*}

ThE discovery of America afforded the European nations vast opportunities for conquest and colonization, but two great powers among them, Spain and England, were foremost in taking up this challenge. Although both nations apparently had a similar background of western culture, it must be remembered that their systems of colonization were rooted in different religious and political philosophies, and that the state of medical science in those two countries varied according to their political development.

Historical analysis seems to indicate that the transfer of European medicine into America during the centuries of colonial administration was influenced more by religious and political factors than by the advanced level of medicine in the colonizing power, and, furthermore, that until the end of the eighteenth century, medicine in America depended almost entirely on European initiative, although it was adapted to the peculiar circumstances of the area.

\section{Spanish Colonization}

At the dawn of the sixteenth century, Spain was the strongest defender of the Gatholic faith which had been the paramount element in the struggle against the Arabs, the expulsion of the Jews, the fight against Reformation, and the proclaimed motive for the evangelical conquest of the American Indians. The political unity around the Castilian king was a secondary factor, which, however, enhanced the absolute monarchy, and provided a single-minded direction to the American adventure. From the scientific point of view the seven centuries of association with the Arabs, before they were finally expelled from Spain, together with the influence of the Jewish translators on her soil, contributed to give Spanish medicine a most distinguished place in the sixteenth century.

In Spanish America medicine was subservient to the spiritual and political aims of the government. The conquest, beginning as the private enterprise of the conquistadors, was followed by the foundation of cities governed by Cabildos, similar to the British town councils, but as a result of the royal appointment of viceroys assisted by Audiencias, the authority of the Cabildos soon withered.

Medical colonization there can only be understood by tracing its roots in the Spanish tradition of Roman Law established in the Iberian peninsula when Spain was itself a colony of Rome; indeed Spain transplanted those same legal and administrative standards into America. By virtue of the Leyes de Indias or American Laws issued from 1542 the administration of every territorial conquest by the Spaniards in the New World fell under the direct control of the Crown,

* Wellcome Research Fellow in the Wellcome Historical Medical Library. 


\section{Francisco Guerra}

in spite of the privileges originally granted to the conquistadors and the democratic nature of the Cabildos. Western medicine was channelled within the same legal framework of centralized power by means of the royal Protomedicato which had absolute authority in medical matters. The Protomedicate was a council, presided over by a head physician, which was empowered to examine practitioners in medicine, surgery, obstetrics, pharmacy and phlebotomy. From their royal foundation in 1570 , these councils kept records of every professional medical man in their area, inspected pharmacies and hospitals, collected reports on local materia medica, and decided on quarantine measures in cases of epidemics. In order to avoid duplicate functioning, the heads of the Protomedicate after 1646 were the professors of medicine in Mexico and Peru, the largest viceroyalties, which also had the finest medical schools.

As a result of the Protomedicate being imported into Spanish America, most of the regulations emanated from metropolitan sources and were included in the Leyes de Indias and Ordinances of the Protomedicate, published in Madrid in $175 \mathrm{I}$; these were supplemented by local proclamations of great interest. The influence of the Protomedicate was such that many years after independence, the former colonies preserved not just the institution, but its officials as well, sympathizers in many cases with the royalist cause.

The Spanish conquest was consolidated by the intermarriage of the indigenous population with the European immigrants; and also by the Encomienda. This system placed under the care of Spaniards a certain number of the native population engaged in work in the fields and mines, in return for some economic compensation and compulsory instruction in the Catholic faith. This method of obtaining labour allowed an exchange of European and American diseases between both groups, and handed the medical care of the destitute Indian to the Spaniards as a Catholic charitable duty. In this way, both monastic orders and priests became involved not only in the spiritual, but in the corporeal health of the masses, so that from that time religious influence has persisted in medical care throughout Spanish America.

\section{British Colonization}

The colonies and trading companies established from England in North America during the sixteenth century lacked the expanding aggressiveness of their southern neighbours. Only with the arrival of the Puritans in 1620 did the religious and political factors that were going to shape the medicine of North America become apparent. The religious concern of the late arrivals was not, however, evangelical, being paradoxically the result of the intolerance of the dogmatic compromise of the Anglican Church. Politically, the English emigrants had a tradition of several centuries of constitutional development before the discovery of America, and they took care to settle in lands outside royal jurisdiction. In this way the Puritans were able to evolve as a political entity with laws emanating from the rights of assemblies rather than the will of the monarch. This philosophy of government spread through the British colonies, taking form only after Locke's propositions in defence of natural rights had been published. This physician and philosopher influenced American political systems indelibly. 


\section{Medical Colonization of the New World}

The religious influence in medicine among the British was not direct; churchmen, it must not be forgotten, had a much higher education than the settlers, and even in medical matters were sometimes superior to medical practitioners. Most of these lacked a medical diploma or proper university training and learned their profession by apprenticeship.

In New England the basic institution of colonial administration was the town council; farther south, the assembly. The settlers remained in groups of similar economic and social extraction, without interest in great territorial expansion or a desire to mix with the Indian population; therefore, their medical problems were similar to those in a homogeneous European village-without the sanitary problems of the large indigenous population-interested in preserving their religious principles and promoting mercantile prosperity. Their community problems, including those of a medical nature, were discussed and decided by the popular vote at the town council. In spite of the royal annulment in 1684 of the Charter of Massachusetts, not only New England, but all the British establishments developed a popular legislature, which also dealt with medicine independently of metropolitan control.

The establishment of British settlers in America early in the seventeenth century coincided with the first medical demonstration of the experimental method in England. Meanwhile, science declined in Spain during the same period owing to dogmatic influences.

\section{The Transfer of Western Medicine}

Certain significant medical data for the period of colonial administration in the New World may be arranged under headings grouping medical practice, hospital establishments, educational institutions, medical publications and research on natural resources with special emphasis on materia medica. The information recording dates and locations may be plotted on the American map allowing a comprehensive view of the events.

The maps show, in the first place, the political organization and boundaries at the height of the viceroyalties' prosperity in the seventeenth century. The dates under the colony's name indicate the span of colonization, although it must be realized that Ganada began as a French colony, to become afterwards a British dominion; the Spanish colonies, except for Cuba and Puerto Rico which remained under Spanish rule until 1898, won independence between 1813 and 1821. The heading of New England actually embraces the thirteen British colonies in North America which, after their independence in 1783 , greatly expanded their territory. Heavy lines mark the boundaries during the colonial period, and the lighter lines present-day frontiers, including, in some cases, several independent nations which sprung from a single viceroyalty.

With this compact information available as a visual aid, it is easier to check the impact of religion and politics upon the evolution of American medicine.

\section{Practice}

Trained graduate physicians reached America with Columbus's first ships, and more followed by every Spanish expedition; qualified practitioners, however, 


\section{Francisco Guerra}

were seldom found in the early British and French settlements. The reason being that under the Spanish crown everything of military importance, including sanitary factors, was carefully considered beforehand, whereas British colonization began as small private enterprises.

The surgical tradition of the Arabs and the use of iron instruments gave the Spaniards considerable advantage in surgery over the Indian use of flint implements, but in the field of clinical medicine, humoral pathology and the therapeutics based upon it were a poor substitute for the aboriginal idea of disease and the treatment available.

Notwithstanding the Spanish priorities in medical practice, the fact remains that large masses of the indigenous population were wiped out in the Caribbean islands and the continent. Smallpox was the greatest scourge among the Indians, and both European nations were equally responsible for its spread, the Spaniards introducing the disease during the conquest of Mexico in 1529, and the British in North America after I633. The spread of epidemics from Europe through America was accelerated in Spanish America by the administrative organization and the close relationship between both races. The origins of syphilis and yellow fever are still under discussion, but the Europeans in turn suffered from the effect of several other new native diseases.

The observation of epidemics at the ports of entry provided an important contribution to medical practice in America; the handling of, for instance, smallpox epidemics by both British and Spaniards gives a clear understanding of how political institutions may affect the evolution of population by the extent of their sanitary measures. From I 720 on, Massachusetts witnessed the inoculation controversy, where the use of smallpox inoculation to prevent natural infection was discussed at the town halls. The procedure, published in the Philosophical Transactions of the Royal Society, was supported in America mostly by the clergy and opposed by some qualified physicians on grounds that inoculation tended to increase the spread of the natural infection. The acceptance of inoculation, in spite of the high mortality attending the technique, followed the whimsical vote of the city fathers in the British colonies, some opposing, others promoting the procedure to control smallpox. Not until much later, when statistics were clearer, was inoculation generally accepted.

In Spanish America the advantage of using the inoculation of human smallpox as a preventive method in the disease was known late in the eighteenth century, and immediately approved by the Protomedicate and therefore the whole medical profession. The importance of a high policy in medical practice, directed by professional bodies, became apparent in this case of the smallpox. After the British discovery of vaccination, the Spanish crown readily arranged, through the Protomedicate, the vaccine expedition from Europe to America, which, in an unbelievably short time, established vaccination all through Spanish America in 1804 .

Medical practice was a free-lance occupation in the British colonies until well after independence; not so in the Spanish area where the Protomedicate kept a watchful control. However, aboriginal medicine, being a great part of the religious and cultural background, was used-as it is still nowadays-by large 


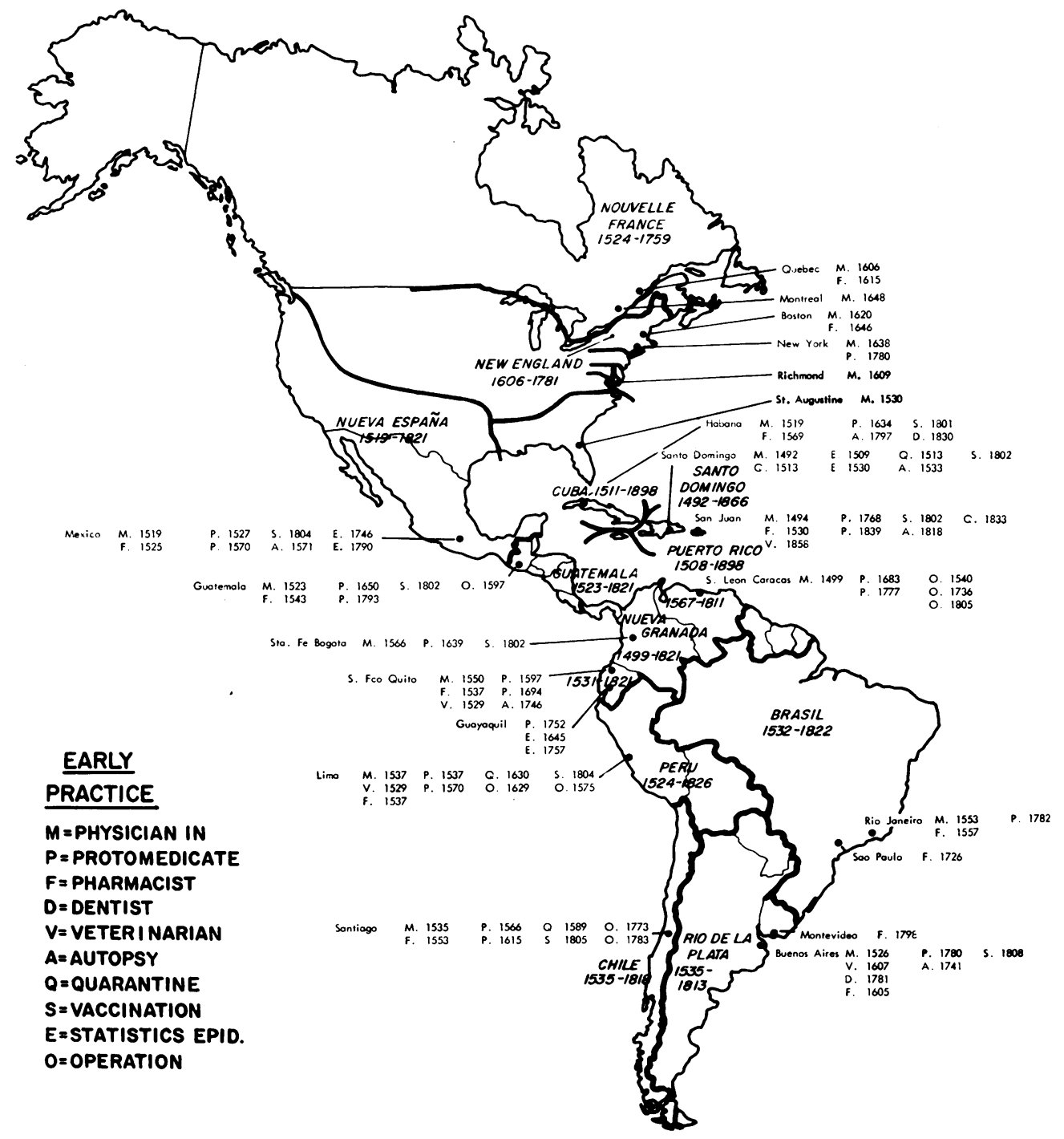




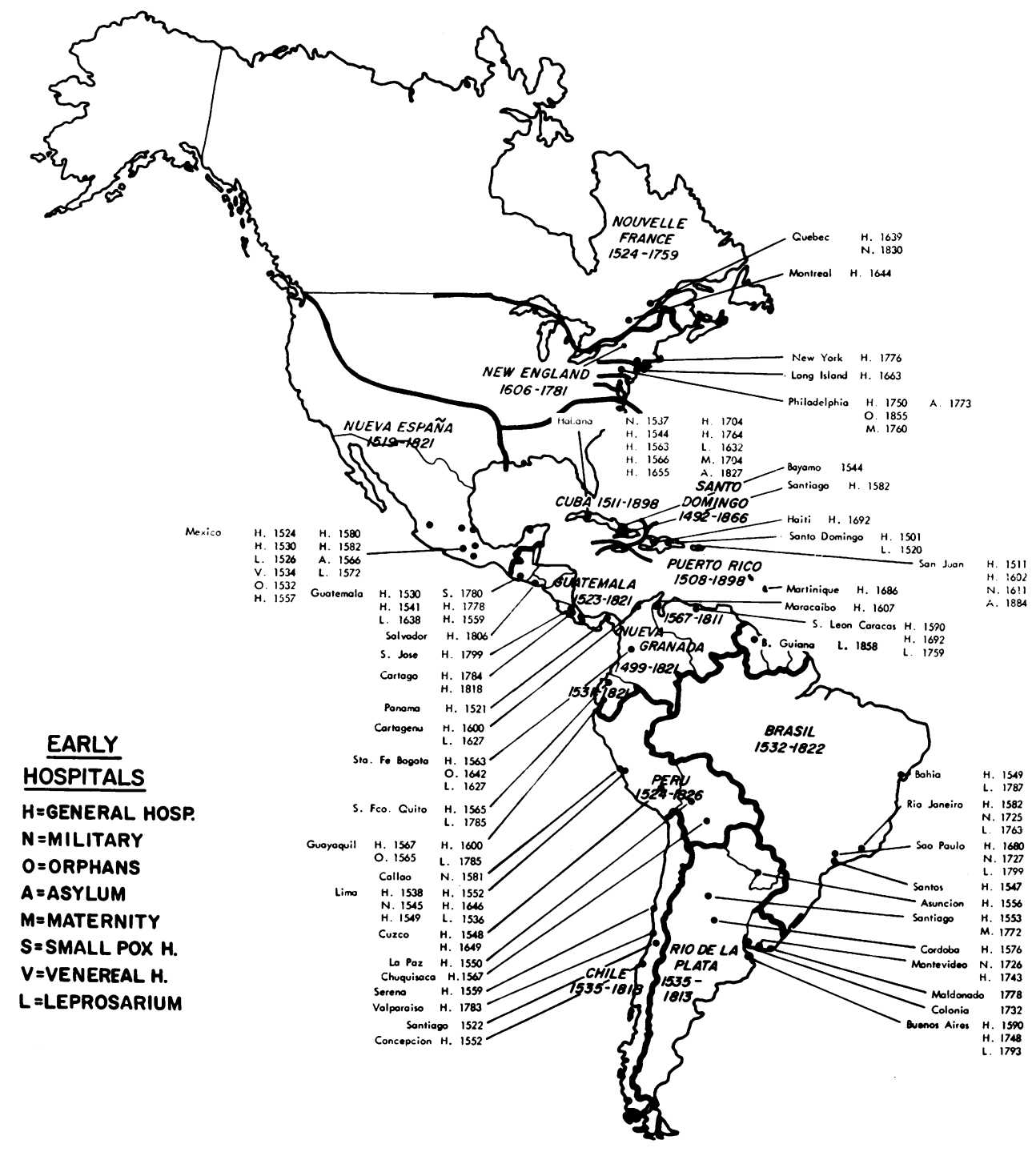




\section{Medical Colonization of the New World}

masses of the population steadfast to the Indian tradition. It may be wise at this point to recall that even the greatest conquistador of all, Cortés, had a great respect for the ability of the Mexican aboriginal physicians and resorted to their therapeutics.

\section{Hospitals}

Excellent hospitals were founded at an early date throughout Spanish America, as is shown in the map. The first was opened in I50I at Santo Domingo and after that there was no community with an average population without a hospital throughout the colonial period. Some of them, such as the Hospital de Jesus in Mexico Gity, are still in daily use. It would not be possible to explain the flourishing of hospital institutions and their deep catholic meaning without the charitable work of the religious orders in charge of them. Printed regulations give a clear idea of their organization, personnel and methods of treatment; some large cities, like Lima, had more hospitals than churches, and in some viceroyalties there were fifteen beds ready to account for the care of every thousand inhabitants. Going through some printed statistics it is possible to gather information on the quality of their services, such as in the case of hospitals attended by members of the order of St. John of God, where mortality was under seven per cent, computed for a population of over one hundred thousand patients.

The foundation of the Pennsylvania Hospital at Philadelphia in 1750 is the first establishment in the British Colonies that may be compared with sister institutions farther south, because the pest-houses and inoculation hospitals which spread throughout the thirteen colonies were not 'hospitals' in our sense of the term. They were opened, often in private houses, on the spur of the moment, under the menace of epidemics, and the practice of the inoculators gave them more the character of dispensaries.

\section{Education}

Although Santo Domingo had, in $153^{8}$, the earliest institution of higher learning in America, the Universities of Mexico and Lima, founded in I55 I, share the glory of being the mothers of western culture in the American hemisphere. Medical education was available, at least in Mexico, even before the Chair of Medicine was created in 1580 ; Lima had one in 1621 and Havana in 1726. Medical students came there from the Spanish or creole classes, although by the eighteenth century, in spite of the regulations on 'blood purity', many a mestiso and mulatto can be found in their rolls.

The controversy between medicine and surgery in Europe was also echoed in Spanish America, and the divisions can be observed in the teaching of those subjects. The identity of the examining board of the university with the one at the Protomedicate gave colonial education there a procedure similar to that standard in the present day. The methods of teaching, the texts, and the doctrines were very much those used in Spain during the sixteenth century, although some clinical work at Lima under Unanue appears really as more advanced in scope than the metropolitan model. The weight of institutional 


\section{Francisco Guerra}

tradition and the rule of the Protomedicate accounts for both the early appearance of medical schools and their subsequent atrophy within the old pattern during the eighteenth century.

In North America, on the other hand, it was during the eighteenth century that young Americans like Morgan and Bard returned to Pennsylvania and New York after being trained at Edinburgh or Leyden, to start medical teaching with a new, modern curriculum. The lack of centralized authority or examining board with power to restrict practice to graduates of the recently created institutions, together with the fact that a great majority of the medical and pharmaceutical profession in those British colonies were self-trained or educated under apprenticeship, limited the social prestige and influence of university education until very recently.

\section{Publications}

Printing was the most important instrument for the colonizing powers of America, both for religious and political aims. Portugal did not dare to have a press in Brazil until 1747 , and this was closed immediately after publishing three works, to be re-established only in 1808 . The British Colonies in North America had a printing shop from 1639 , but considering the background of the Spanish colonization it is amazing to find printing shops operating in Mexico from 1539, and very shortly in many other places in Spanish America. In those years the nailing of the ninety-five propositions of Luther in 1517 could still be heard. It must be added that a good many of the earliest printers were coming from areas of the Spanish Empire tainted with Protestantism. The only answer could be the extended use of the early press in the publication of Catholic doctrines for the Indians and of books on Indian languages to help in the colonization.

Medical publications started in Mexico with the Phisica Speculatio of Veracruz in 1557 and by the middle of the seventeenth century show a superb repository. Mexico had also the first medical journal, the Mercurio Volante, in I772, but the publications that give the characteristic flavour to medical literature in America are not the big books but the small pamphlets. In the British Colonies medical imprints appear about a century later in Massachusetts, not until 1785 in Quebec, Canada, and finally in 1809 in Rio de Janeiro, Brazil. The map offers a varied landscape of cities with printing shops and the most important titles of medical works issued. A figure in parentheses is given for each area, indicating the approximate number of medical imprints published during the colonial period.

However, some notes are pertinent in this respect. The thirteen British Colonies obtained their independence in 1783 while most Spanish American Colonies did not gain it until 1821 . Cuba, on the other hand, remained under the Spanish crown until the end of the nineteenth century. The knowledge of medical printing in America is far from complete and some Caribbean areas, such as Jamaica or Haiti, were more important centres of medical printing than much larger colonies like Canada or Brazil, and with more interesting subjects to offer. 


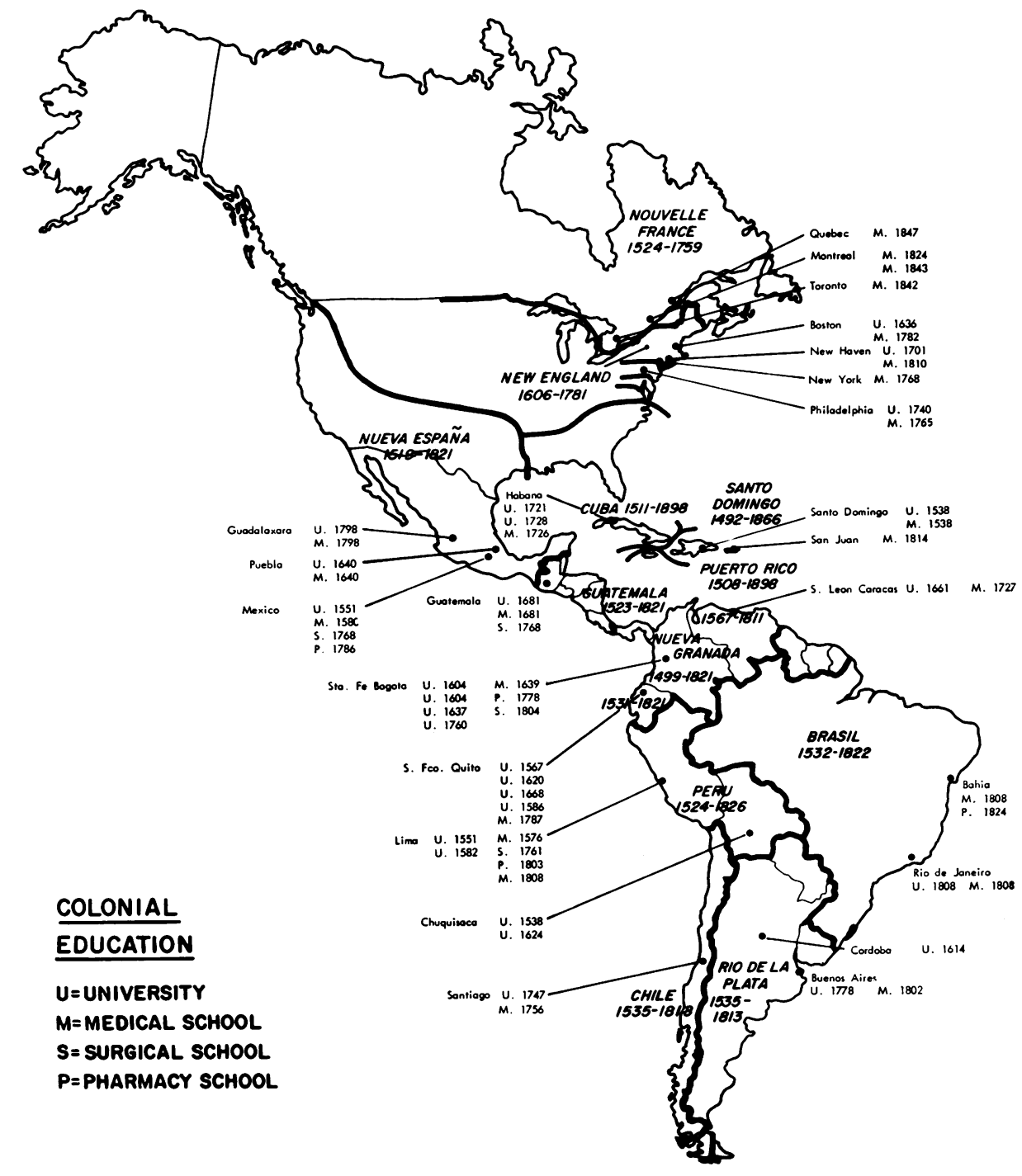




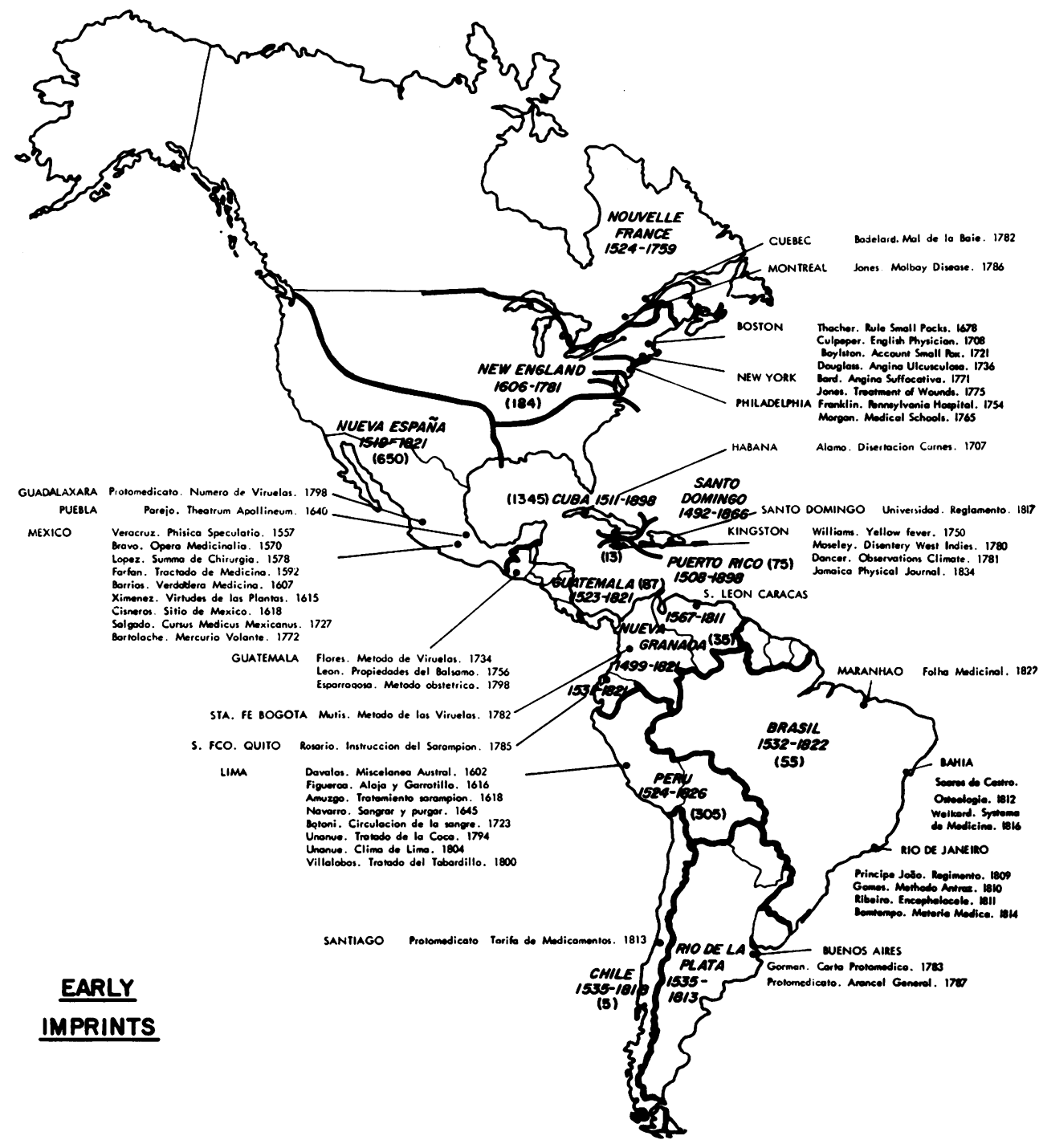




\section{Medical Colonization of the New World}

Research

A striking characteristic of Spanish America is, perhaps, the numerous expeditions undertaken during the colonial period aimed at enlarging the knowledge of natural resources. Historians seldom appreciate the fact that one of the motives for Columbus's voyages was the Spanish need to secure the spices and oriental drugs direct, and so to avoid dependence on the Venetians for items of high importance in the preservation of the food and health of the Spanish armies. The conquistadors and their writers described the New World not only as the sources of gold and precious stones, but also as the land of the marvellous Balsam to cure wounds, the cathartic Jalap root and the strange Coca. These three were well known to the Indians as also were the anthelmintic properties of Chenopod, the antidysenteric action of Ipecac and the paralysis produced by Curare. However, the same cannot be said about Cinchona, which was known to the Europeans by the middle of the seventeenth century. It is a bitter turn of fate that a plant, the most American of all, Tobacco, which started to be used as a remedy for cancer, is now being accused of inducing the evil it was expected to cure.

The contributions made in other areas in the field of therapeutics were very limited. Only in the south of the thirteen British Colonies did medicine try to incorporate local remedies used in the plantations, which brought into the European pharmacies the root of Seneca.

The religious influence on medical research becomes clear when it is realized that, with the exception of a few highly qualified expeditions organized by the Spanish crown, most of the early geographical, botanical, ethnographic and general descriptions of scientific interest came from the hands of Catholic friars engaged in the propagation of their faith. Their chronicles have remained for almost five centuries the best sources of reference for our basic knowledge of America and American civilization.

Politics also have an effect on medical research in that continent. The Spanish government regarded all information pertaining to America as a matter of high political secrecy. It was important that the English, or any other foreign power, should not learn of the movements of the Spanish treasure-ships, nor the locations or resources of Spanish establishments, because that would be to supply pirates and privateers with a guidance in their enterprises; but the medical information pertaining to American drugs was also a matter of great political interest, and the Spanish books referring to them were readily translated into English or French.

Politics also had a curious twist because, during the sixteenth and seventeenth centuries, the Spanish crown, in the hands of the Austrian dynasty, considered both British and French as its enemies and Germans and Flemish as its natural allies. Exceptions were made for the Gatholic Irish during the eighteenth century when many of them received high positions, and became viceroys and protomedicates. Therefore, Spain handed the monopoly of the two most important American drugs, the antisyphilitic Sarsaparilla and Guayaco wood, to the German banker Fugger, and the Balm went to the Welsers. However, in the eighteenth century, when the Spanish crown fell to the Bourbon dynasty, 


\section{Francisco Guerra}

French scientists poured into the Spanish institutions in the peninsula or went to America, particularly under Charles III and IV, as a result of the so-called Bourbon 'pacte de famille'.

\section{GONGLUSIONS}

The religious denominations of the colonizing powers in America, both Catholics and Protestants, had a considerable influence upon the development of medicine in the New World, and, furthermore, gave to the practice and to the present-day institutions distinctive characteristics that evolved from the colonial period. The political systems of the colonizers were also important in forming medical policies and embodying them in legislation.

Finally, it was the European and not the indigenous element which dominated the shaping of medicine in the American continent during the years of colonization. 


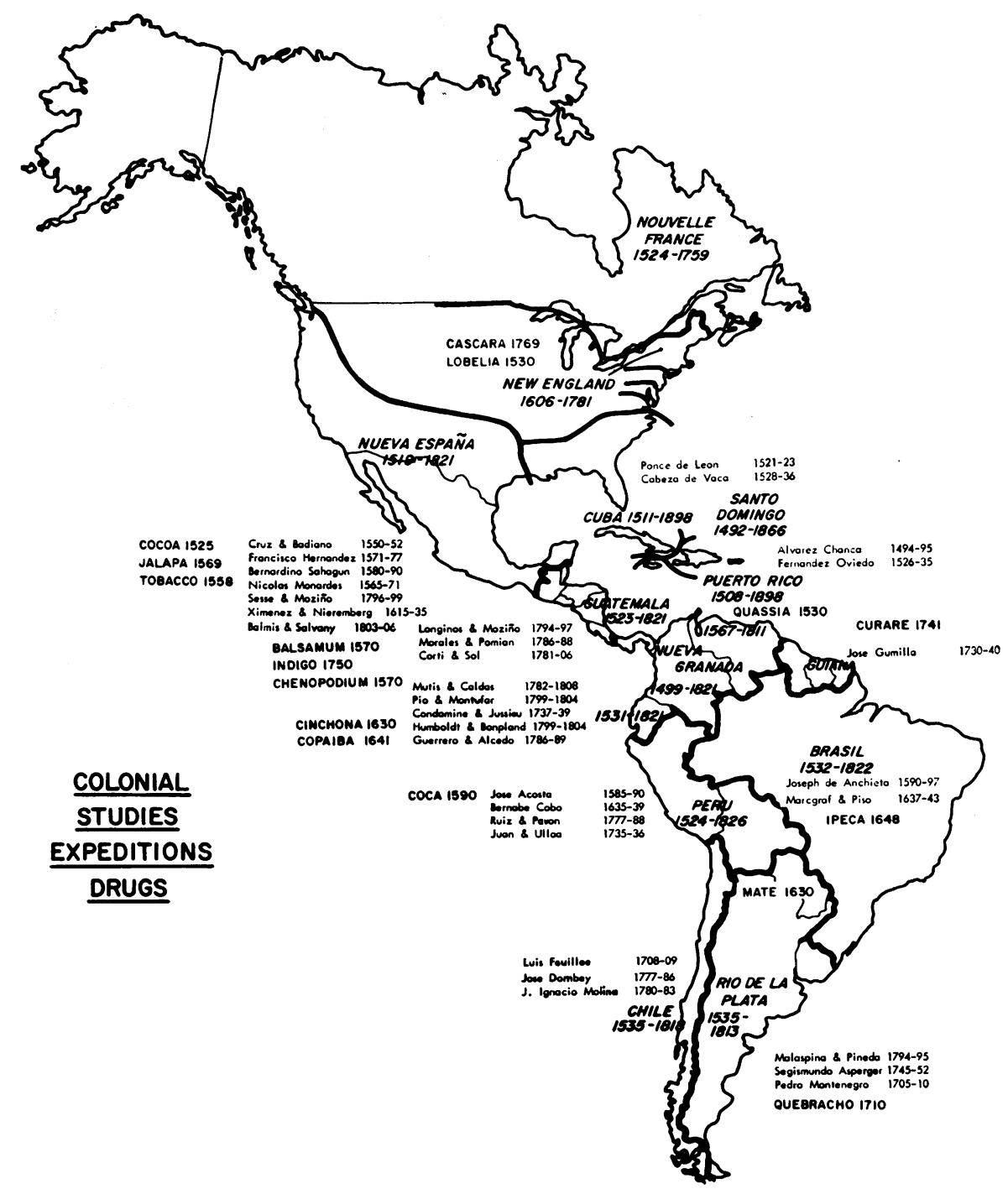

